\title{
O POTENCIAL DE RESERVAÇÃO DE ÁGUA SUBTERRÂNEA NA PLANÍCIE DE INUNDAÇÃO DO RIO ATIBAIA, DISTRITO DE BARÃO GERALDO, CAMPINAS, SP
}

Luís Eduardo de Oliveira Muraro후 ${ }^{1}$ Sueli Yoshinaga Pereira²; Paulo Ricardo Brum Pereira ${ }^{3}$

Resumo Os aquíferos aluvionares geralmente são apresentados como áreas de pouca significância pela sua pequena extensão e descontinuidade. No entanto, decorrente de seu posicionamento topográfico e proximidades de rios, geralmente áreas de descarga de água subterrânea (rios efluentes), podem ser reservatórios de água estratégicos e relevantes. No presente estudo considerações foram feitas sobre a capacidade de reservação da planície aluvionar do rio Atibaia, na região limítrofe entre os municípios de Campinas, Jaguariúna e Paulínia. A área da planície apresenta cerca de $20 \mathrm{~km}^{2}$ e espessura média de 50 metros. As reservas ativa $\left(0,031 \mathrm{~m}^{3} / \mathrm{s}\right)$, permanente $\left(3,09 \mathrm{~m}^{3} / \mathrm{s}\right)$, total $(12,4$ $\left.\mathrm{m}^{3} / \mathrm{s}\right)$ e reserva disponível $\left(3,103 \mathrm{~m}^{3} / \mathrm{s}\right)$ foram estimadas. Os valores resultantes são extremamente altos e indicam uma elevada potencialidade de explotação para abastecimento público. Há relatos de problemas da qualidade destas águas, muitas vezes são ferruginosas e relativamente ácidas, sendo necessárias a remoção de ferro e neutralização para deixá-las potáveis. Assim esta disponibilidade merece maiores estudos para sua real quantificação.

Abstract The alluvial aquifers are usually presented as insignificant areas for its small extension and discontinuity. However, due to their topographic position and nearby rivers, usually groundwater discharge areas (effluent streams) may be relevant and strategic groundwater reservoirs. In this study we were taken into consideration the reservation capacity of the alluvial plain of the Atibaia River, in the border region between the cities of Campinas, Jaguariúna and Paulínia. The area of the plain presents about $20 \mathrm{~km}^{2}$ and 50 meters average thickness. The active $\left(0,031 \mathrm{~m}^{3} / \mathrm{s}\right)$, permanent $(3.09$ $\left.\mathrm{m}^{3} / \mathrm{s}\right)$, total $\left(12.4 \mathrm{~m}^{3} / \mathrm{s}\right)$ and available reserves $\left(3,103 \mathrm{~m}^{3} / \mathrm{s}\right)$ were estimated. The resulting values are

\footnotetext{
1 Mestrando. Instituto de Geociências. Rua João Pandiá Calógeras, 51. CEP 13083-870. Campinas, SP. Fone: 55 19 3521 4698. E-mail: luis.muraro@yahoo.com.br.

2 Profa. Dra. Instituto de Geociências. Rua João Pandiá Calógeras, 51. CEP 13083-870. Campinas, SP. Fone: 55 19 35214698. E-mail: sueliyos@ige.unicamp.br

${ }^{3}$ Dr. Instituto Florestal Secretaria do Meio Ambiente do Estado de São Paulo. Rua do Horto, 931. São Paulo, SP. Fone: 55 11 22318555. CEP: $02377-$ 000. E-mail: paulobrumpereira@gmail.com
} 
extremely high and indicate a high potential for groundwater exploitation of public supply. There are reports of quality problems of groundwater, often ferruginous and relatively acidic, requiring iron removal and neutralization to make them drinkable. So this availability deserves further study to its actual quantification.

\section{Palavras-Chave}

Aquífero aluvionar, reservas, potencial de explotação.

\section{1 - INTRODUÇÃO}

Os aquíferos aluvionares geralmente são apresentados como áreas de pouca expressão no que se refere a outros aquíferos pela sua pouca extensão e descontinuidade. No entanto, decorrente de sua posicionamento topográfico e proximidades de rios, geralmente áreas de descarga de água subterrânea (rios efluentes) são reservatórios de água estratégicos muito utilizados em regiões áridas ou semiáridas e pela população local. Desta forma, o presente estudo objetiva fazer algumas considerações sobre a capacidade de reservação da planície aluvionar do rio Atibaia, na região limítrofe entre os municípios de Campinas, Jaguariúna e Paulínia, situada ao norte do primeiro município citado.

Sob a grande planície de inundação do Rio Atibaia, situada ao norte do Distrito de Barão Geraldo existem diferentes compartimentações geológicas. Estes corpos e formações rochosas possuem em seu interior diferentes aquíferos, com características hidrodinâmicas e capacidade de aramazenamento diferenciadas. Encontram-se aí litologias como diabásios, granitos, arenitos que se situam ao longo da área e que embasam esta planície aluvionar.

Este artigo visa avaliar as condições e reservação da planície aluvionar e dos aquíferos soto postos, considerando também as características fisiográficas dessa porção da bacia hidrográfica do rio Atibaia.

\section{2 - ÁREA DE ESTUDO}

A área de estudo encontra-se à $34 \mathrm{~km}$ de distância do centro da cidade de Campinas. Parte integrante da planície aluvionar do rio Atibaia, faz o limite entre os municípios de Campinas, Jaguariúna $(\mathrm{N})$ e Paulínia (NO). Está localizada entre as coordenadas $22^{\circ} 44^{\prime} 33^{\prime}$ 'S, 4707'28”O;

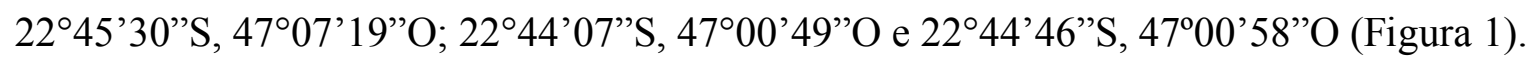


Do centro do distrito de Barão Geraldo dista $17 \mathrm{~km}$ e os seus acessos são pela Rodovia Campinas-Paulínia (SP-332), Rodovia Campinas-Mogi Mirim (SP-340) e a estrada municipal da Rhodia, além de estradas vicinais e de terra. Possui uma área total de aproximadamente $20 \mathrm{~km}^{2}$.

A planície em sua margem direita do rio Atibaia, pertencente ao município de Jaguariúna, é uma área extensa de cultivo de cana de açucar para produção de açucar e etanol. Já na margem esquerda do rio, existem ocupação humana em bairros rurais como Condomínio Vale das Garças, Chácaras Piracambaia (I e II) e rua Peroba. Estas ocupações são caracterizadas por sítios, chácaras e pequenas moradias, estimando uma população de 3 mil moradores. A água de abastecimento provém de poços tubulares profundos de propriedade da SANASA (Companhia de Águas de Campinas), no Condomínio Vale das Garças e por poços tubulares particulares e domésticos para a população restante.

A análise do estudo consiste nos limites da bacia hidrográfica da planície aluvionar da porção média do rio Atibaia, que possivelmente está encaixada em estruturas (falhas e fraturamentos), a partir de soleira de diabásio a jusante (oeste da área) que proporcionou um certo barramento do rio Atibaia, e dessa forma o desenvolvimento da planície.

Em termos hidrogeológicos, na porção leste da área, o embasamento cristalino é composto por granitos das suítes graníticas de Morungaba e Jaguariúna, cujos contatos são tectônicos de direção NE, relacionados a Zona de Cisalhamento Campinas-Valinhos (Governo do Estado de São Paulo 2009). Rochas de origem sedimentar do Subgrupo Itararé ocorrem na porção sul e central, e caracteriza-se na porção centro-norte predominantemente pelos arenitos médio-grossos (Iam) e na porção centro-sul por diamictitos maciços, lamitos e ritmitos areno-silto-argilosos ou silto-argiloso (CPiD). Os diabásios ocorrem oeste, leste e norte da área de estudo. Os sedimentos cenozóicos da planície do rio Atibaia (Qa), compõe-se principalmente por depósitos de aluvião e colúvios oriundos das alterações dos cursos de água e transporte e lixiviação dos solos.

O canal de drenagem do rio Atibaia possui um padrão de estruturação, principalmente nas porções norte e leste da planície. 


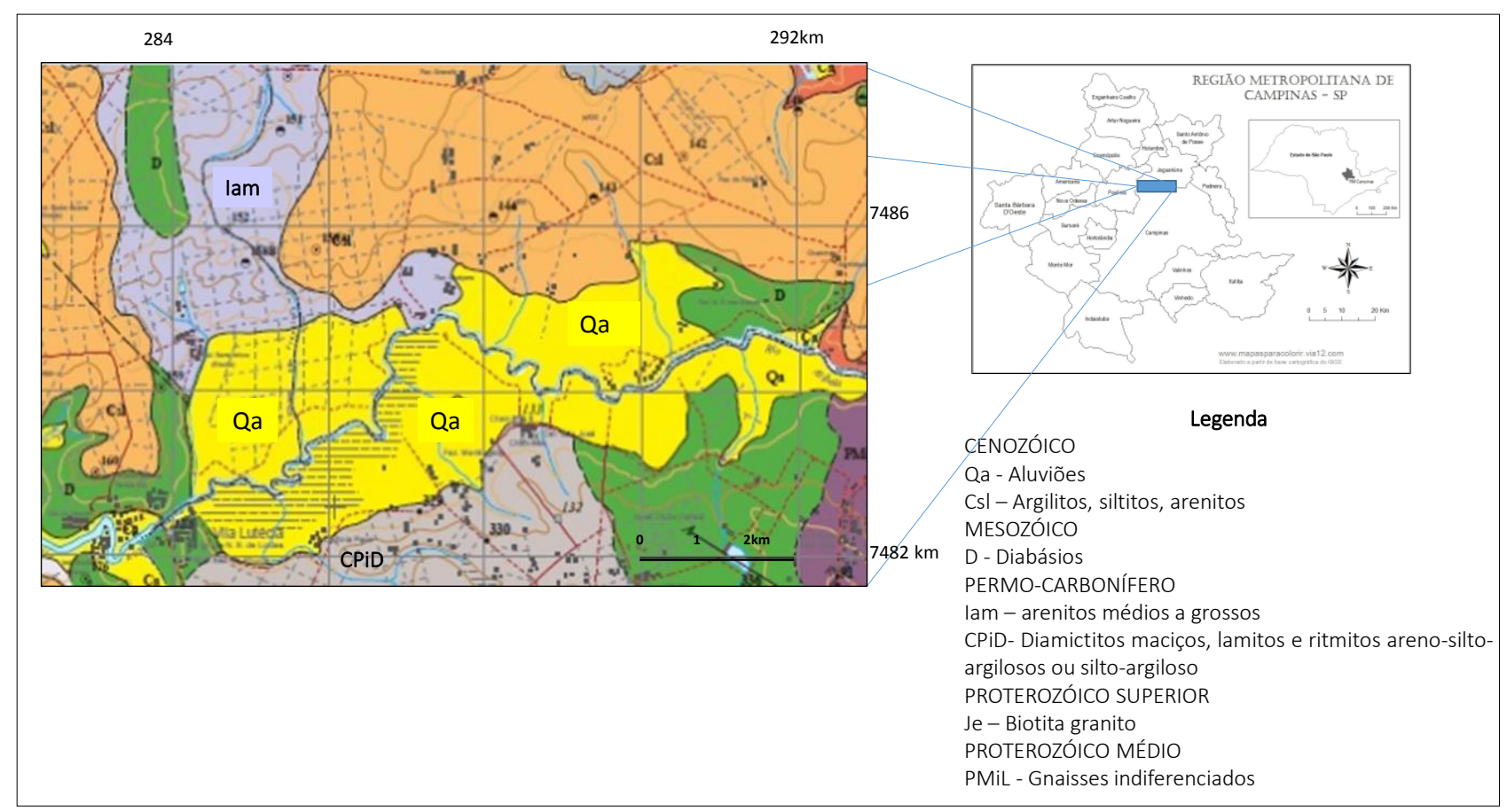

Figura 1 - Localização da área de estudo e geologia (Fonte: modificado de Governo do Estado de São Paulo, 2009).

\section{3 - MÉTODO}

Os dados utilizados estão baseados em documentação de direito público de diversas instituições públicas e literatura científica sobre a região. Para o entendimento desse estudo, foram consultados as referencias bibliográficas sobre hidrogeologia da região e proximidades do local de estudo e cadastros de poços, visando verificar as potencialidades dos aquíferos nas proximidades da área.

A estimativa de reservas foram calculadas pela metodologia desenvolvida por Governo do Estado de São Paulo (2009). Reserva Permanente foi adotada pelo autor como sendo "o volume de água acumulado no aquífero, não variável em decorrência da flutuação sazonal da superfície potenciométrica"; já a Reserva Ativa é “a quantidade de água armazenada no aquífero e renovada anualmente a cada ciclo hidrológico (corresponde à recarga sazonal), determinantes para a manutenção do escoamento de base dos rios. A Reserva Explotável é a "quantidade máxima de água que poderia ser extraída de um aquífero, sem riscos de prejuízo ao manancial”.

A Reserva Permanente é definida como o produto da multiplicação do volume (espessura $\mathrm{x}$ área) e da porosidade efetiva (0,25 para o aquifero sedimentar e 0,07 para o aquifero fraturado e diabásio).

A Reserva Ativa utilizado a estimativa proposta por Lopes (1994) e os dados foram provenientes por Yoshinaga-Pereira (1996), de escoamento básico, porcentagem da área do aquífero (por área de drenagem do posto fluviométrico 4D 009), a área do aquífero analisado. 
Por fim, a disponibilidade hídrica subterrânea é "o volume máximo que pode ser extraído dos aquíferos sem causar risco de exaustão ou provocar danos ambientais irreversíveis e, na concepção atual devem abranger parte das reservas ativas e parte das reservas permanentes dos aquíferos. " Foi adotado a taxa de $25 \%$ para a Reserva Total calculada (Lopes 1994).

\section{4 - RESULTADOS}

\section{1 - Hidrogeologia}

A planície aluvial encontra-se sobreposta as rochas sedimentares, corpos de diabásio e rochas cristalinas da região norte/noroeste do município de Campinas. De acordo com a proposta de Governo do Estado de São Paulo (2009), a área de estudo abarca os aquíferos, caracterizados sinteticamente na Tabela 1.

Tabela 1 - Síntese das características dos aquíferos na área de estudo

\begin{tabular}{|c|c|c|}
\hline Aquifero/*Aquitarde & Litologias & Características hidrogeológicas \\
\hline Aluvionar & $\begin{array}{l}\text { (Qa) depósitos de aluvião e } \\
\text { colúvios (sedimentos variados) }\end{array}$ & $\begin{array}{l}\text { Aquífero poroso, anisotrópico, } \\
\text { descontínuo e de pequena extensão, } \\
\text { nível de água raso a aflorante, elevada } \\
\text { permeabilidade. }\end{array}$ \\
\hline *Coluvionar & $\begin{array}{l}\text { (Csl) - argilitos, siltitos e } \\
\text { arenitos }\end{array}$ & $\begin{array}{l}\text { Aquífero poroso, heterogêneo e } \\
\text { anisotrópico, contínuo e de pequena } \\
\text { espessura, nível de água variável, de } \\
\text { acordo com a altitude, permeabilidade } \\
\text { variada tendendo a baixa. Pode ser } \\
\text { considerado aquitarde. }\end{array}$ \\
\hline DIABÁSIO** & $\begin{array}{l}\text { (D) Rochas de coloração cinza } \\
\text { escura, podem ocorrer na região } \\
\text { como formas de sills ou diques }\end{array}$ & $\begin{array}{l}\text { Porosidade fissural, aquífero } \\
\text { heterogêneo e anisotrópico, } \\
\text { permeabilidade variável dependendo } \\
\text { da ocorrência de fraturas. }\end{array}$ \\
\hline TUBARÃO & $\begin{array}{l}\text { (Iam) Arenitos médios a } \\
\text { grossos }\end{array}$ & $\begin{array}{l}\text { Aquífero poroso, de extensão regional, } \\
\text { muito heterogêneo. Provavelmente } \\
\text { pode apresentar boas vazões relativas } \\
\text { ao aquífero, pela composicão dessas }\end{array}$ \\
\hline
\end{tabular}


fácies, que apresenta sedimentos com

(CPiD) Diamictitos maciços, boa permeabilidade.

lamitos e ritmitos areno-silto- Aquífero poroso, de extensão regional, argilosos ou silto-argiloso muito heterogêneo. Provavelmente pode apresentar baixas permeabilidades e baixas vazões relativas ao aquífero, pela composição dessas fácies, que apresenta sedimentos com argilosos.

FRATURADOS Je - Biotita granito e PMiL - Aquífero fraturado e de extensão Gnaisses indiferenciados regional. Porosidade fissural, aquifero heterogêneo e anisotrópico, permeabilidade variável dependendo da ocorrência de fraturas

(fonte: Governo do Estado de São Paulo 2009). ** Obs.: os diabásios, que compõem os Aquíferos Fraturados, foram destacados devido sua importância na área de estudo.

As aluviões da planície de inundação encontram-se sobre o embasamento cristalino das suítes graníticas Itapira e Jaguariúna. Compõem-se ainda de grandes intrusões de diabásio e sedimentos do Subgrupo Itararé.

De acordo com Yoshinaga-Pereira (1996) os poços dos aquíferos fraturados apresentam capacidade específica média de $0,28 \mathrm{~m}^{3} / \mathrm{h} / \mathrm{m}$. Transmissividades calculadas em alguns poços determinaram valores entre 0,13 a $6,85 \mathrm{~m}^{2} / \mathrm{dia} / \mathrm{m}$ expressando a grande heterogeneidade do aquífero por porosidade fissural. O Aquífero Tubarão, na área representado pelo Aquífero Itararé apresenta capacidade específica média de $0,25 \mathrm{~m}^{3} / \mathrm{h} / \mathrm{m}$, também apresentando grande heterogeneidade de produção decorrente de sua complexidade de ambientes de sedimentação. O Aquífero Diabásio, na região apresenta valores de capacidade específica média de $0,78 \mathrm{~m}^{3} / \mathrm{h} / \mathrm{m}$, com grande variação de valores deste parâmetro decorrente de sua característica fissural. Em geral apresenta baixa produtividade.

Por fim os sedimentos de idade Cenozóica (principalmente coberturas sedimentares) apresentam espessura de 35 a 40 m, situam-se em áreas elevadas de recargas locais.

\section{2 - Aquífero aluvionar do rio Atibaia}


O aquifero aluvionar do rio Atibaia consiste de uma extensa área, com cerca de $20 \mathrm{~km}^{2}$, onde vivem na margem esquerda do rio, aproximadamente 3 mil habitantes (estimativa tendo base Prefeitura Municipal de Campinas, 2006). Bairros rurais com haras, chácaras, sítios de alto padrão se misturam com bolsões de simples moradias de baixo padrão, nesta área pertencente ao município de Campinas (Figura 2). A planície em sua margem direita, no município de Jaguariúna, pertence a empresa de Paulínia e está arrendada para cultura de cana-de-açúcar para produção de etanol.

A planície apresenta forma estreita e encaixada no bordo do rio, e gradativamente vai alargando-se ao longo do sentido montante-jusante, atingindo sua largura máxima próximo à Estrada da Rhodia. O represamento das águas deve-se à existência de uma soleira litoestrutural formada diabásios junto à Estrada. Neste ponto ocorre uma grande dissecação da superfície devido a ação do próprio Atibaia e suas inundações (Governo do Estado de São Paulo, 1993). A Figura 2 mostra que a oeste da planície apresenta menores altitudes, e a leste, as partes mais altas da planície. Em visitas à área em periodos de chuvas foram observadas grande aporte de escoamento superficial em direção a planície, provenientes das vertentes constituídas por pastagem e pasto sujo.

Há presença de poços tubulares profundos na área, decorrente da ausência de rede de água potável. Nas áreas não abastecidas por estes poços, utilizam-se águas provenientes de poços domésticos.

No cadastro do Instituto Geológico (Governo do Estado de São Paulo, 1995), destaca-se o poço do Condomínio Vale das Garças. Daleffe (2003) cadastrou dois poços tubulares profundos na planície: um situado no bairro Chácaras Piracambaia I (proprietário José Coser) e no Condomínio Vale das Garças (poço antigo da empresa de águas de Campinas, SANASA). As principais características dos poços são apresentadas na Tabela 2.

Tabela 2 - Características dos poços perfurados na planície do rio Atibaia na área de estudo.

\begin{tabular}{|l|c|c|c|}
\hline Poço/ Local & Profundidade (m) & NE/ ND $(\mathrm{m})$ & $\mathrm{Q}\left(\mathrm{m}^{3} / \mathrm{h}\right) / \mathrm{Q} / \mathrm{s}\left(\mathrm{m}^{3} / \mathrm{h} / \mathrm{m}\right)$ \\
\hline Condomínio Vale das Garças & $102 *$ & $1,0 / 90^{*}$ & $15 / 0,1685^{*}$ \\
(75 m de sedimentos e restante, & & $3,7 / 7,32^{* *}$ & $44 / 12,15^{* *}$ \\
diabásio) & & & \\
\hline $\begin{array}{l}\text { José Coser/ Ch. Piracambaia I } \\
\text { (sem informação) }\end{array}$ & - & $2,0 / 5,0^{* *}$ & $16,5 / 5,5^{* *}$ \\
\hline
\end{tabular}

*Governo do Estado de São Paulo (1995); ** Daleffe (2003)

Há uma discrepância entre os dados do poço do Condomínio Vale das Garças. No entanto, as informações de Daleffe (2003) foram obtidas diretamente da empresa, de onde foram retiradas as informações de teste de bombeamento e foram consideradas.

Os poços apresentam elevada produção e transmissividades, anômala em relação à média dos aquíferos regionais. Em visita a área são reportadas elevadas vazões em poços domésticos. 
Os poços tubulares estão apresentados na Figura 2.

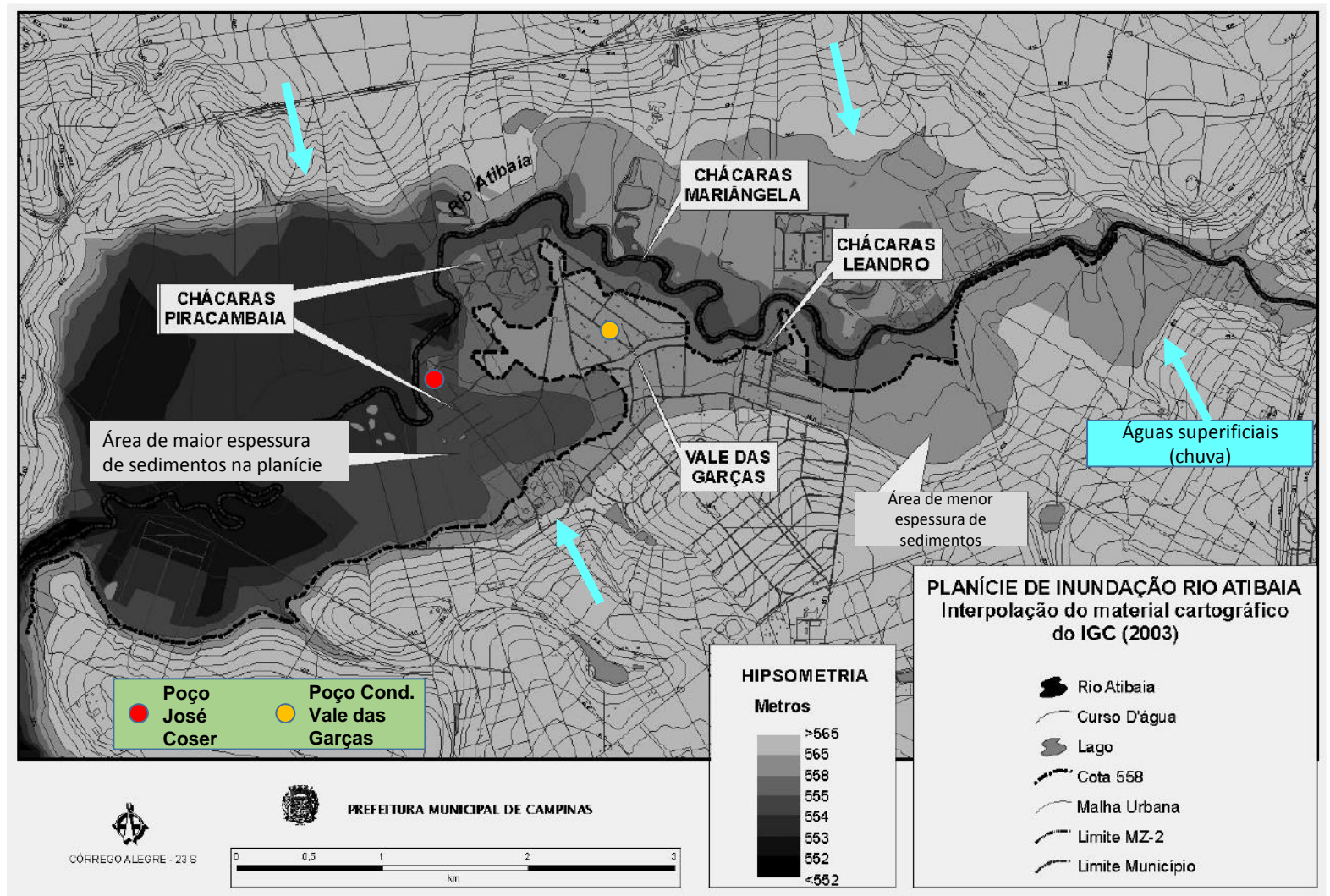

Figura 2 - Hipsometria da Área de estudo com a localização dos poços tubulares profundos

\section{3 - Estimativa de reservação e disponibilidade de água subterrânea na planície}

Na estimativa da reserva permanente da planície da área de estudo, foi considerado uma espessura média de 50 metros, área de $20 \mathrm{~km}^{2}$ e porosidade efetiva de 0,25 (areia média, de acordo com Fetter, 2001). A espessura dos sedimentos na parte profunda da área foi fornecida pelo poço do Sr. José Coser ( 75 metros de sedimento) e assim foi estimado uma espessura média de 50 metros de sedimentos. A Reserva Ativa foi baseada nas informações de Yoshinaga-Pereira (1996) e Lopes (1994).

A Tabela 3 apresenta os resultados das estimativas de reservas para a planície.

Tabela 3. Reservas estimadas para a área de estudo.

\begin{tabular}{lllll}
\hline Aquífero & $\begin{array}{l}\text { Reserva Permanente } \\
\left(\mathrm{m}^{3} / \mathrm{s}\right)\end{array}$ & $\begin{array}{l}\text { Reserva Ativa } \\
\left(\mathrm{m}^{3} / \mathrm{s}\right)\end{array}$ & $\begin{array}{l}\text { Reserva Total } \\
\left(\mathrm{m}^{3} / \mathrm{s}\right)\end{array}$ & $\begin{array}{l}\text { Reserva Disponível } \\
\left(\mathrm{m}^{3} / \mathrm{s}\right) /\left(\mathrm{m}^{3} / \mathrm{dia}\right)\end{array}$ \\
\hline $\begin{array}{l}\text { Planície } \\
\text { Diabásio/ }\end{array}$ & 7,93 & 0,000735 & 7,9307 & $1,983 / 171.331,2$ \\
Fraturados & 4,44 & 0,03 & 4,47 & $1,12 / 96.768$
\end{tabular}


(aquiferos

sotopostos)

Total

3,09

0,030735

12,4007

$3,103 / 268.099,2$

Estes valores são extremamente altos e são estimativas que devem ser detalhadas e acuradas, porém os valores indicam uma elevada potencialidade de explotação para abastecimento público. Em visitas à área de estudo, há relatos de problemas da qualidade destas águas, muitas vezes são ferruginosas e relativamente ácidas, sendo necessárias desferruginização e neutralização para deixálas potáveis.

Com base nos valores apresentados, considerando o uso diário de água/pessoa de 200 1/dia, estima-se o abastecimento para 1.340 .000 pessoas (próximo ao número da população de Campinas, de 1.080.113 hab. (IBGE, http://cidades.ibge.gov.br/painel/painel.php?codmun=350950, acesso 17/06/2016).

\section{5 - CONCLUSÃO}

A planície aluvionar e os aquíferos sotopostos do rio Atibaia na porção norte do Distrito de Barão Geraldo apresenta uma elevada capacidade de reservação de água, bem como uma disponibilidade anômala. A conformação da planície e extensão (uma bacia sedimentar recente) pode receber águas de escoamento superficial das vertentes, da recarga das águas de chuva e do próprio rio Atibaia. A baixa transmissividade dos aquíferos sotopostos (diabásio e granito) pode favorecer o armazenamento das águas na planície e mantê-la sempre saturada.

A capacidade de reservação estimada para explotação das águas subterrâneas indica um aquífero de excelência e potencial de abastecimento. No entanto o presente estudo destaca a necessidade de maiores estudos tanto para quantificar com maior precisão este potencial, bem como a avaliação para qualidade destas águas.

\section{6 - REFERÊNCIAS BIBLIOGRÁFICAS}

DALEFFE, D. Caracterização hidrogeológica dos aquíferos da região de Barão Geraldo. Campinas. Trabalho de Conclusão de Curso. Universidade Estadual de Campinas (Graduação em Ciências Exatas e da Terra). 2003.

FETTER, C.W. Applied Hydrogeology. $4^{\text {th }}$ Ed. Prentice Hall. 2001. 598p. 
GOVERNO DO ESTADO DE SÃO PAULO. Elaboração do Plano Diretor de aproveitamento de recursos hídricos para a Macrópole Paulista. Nota Técnica - Metodologia para o Cálculo da Disponibilidade Hídrica Subterrânea. Fev. 2009. 16p.

GOVERnO DO ESTADO DE SÃO PAUlO. Mapa Geológico do Município de Campinas, Volume II, Relatórios Técnicos. 127 p. + mapa. 2009.

GOVERnO DO ESTADO DE SÃO PAULO. Mapa de Águas Subterrâneas do Estado de São Paulo - SP, escala 1:1.000.000. DAEE, IG, IPT, CPRM. Nota explicativa + mapa. 2005.

GOVERNO DO ESTADO DE SÃO PAULO. Subsídios para o planejamento regional e urbano do meio físico na porção média da Bacia do rio Piracicaba, SP. Relatório Técnico Instituto Geológico SMA. 1995. 4v.

GOVERNO DO ESTADO DE SÃO PAULO. Subsídios do meio físico-geológico ao planejamento de Campinas (SP). Relatório Técnico Instituto Geológico SMA. 1993. 3v.

INSTITUTO BRASILEIRO DE GEOGRAFIA E ESTATÍSTICA (IBGE). Cidades. http://cidades.ibge.gov.br/painel/painel.php?codmun=350950, acesso 17/06/2016.

LOPES, M.C. Condições de ocorrência de água subterrânea nas bacias dos rios Piracicaba e Capivari. Universidade de Campinas (Dissertação de Mestrado). 83p. 1994.

PREFEITURA MUNICIPAL DE CAMPINAS. 2006. Plano Diretor. http://www.campinas.sp.gov.br/governo/seplama/publicacoes/planodiretor2006/index.php, acesso 17/06/2016.

YOSHINAGA-PEREIRA, S. Proposta de representação cartográfica na avaliação hidrogeológica para estudo de planejamento e meio ambiente, exemplo da Região Metropolitana de Campinas, SP. Universidade de São Paulo (Tese de Doutorado). 183p. 1996. 